\title{
Nonlinear analysis of FGM plates using generalised higher order shear deformation theory
}

\author{
Singam Srividhya* \\ Department of Civil Engineering, \\ IIT Hyderabad, \\ Telangana, 502285, India \\ Email: ce15mtech11021@iith.ac.in \\ *Corresponding author
}

\section{Basant Kumar and R.K. Gupta}

Advanced Systems Laboratory,

DRDO, Kanchanbagh PO,

Hyderabad - 500058, India

Email: ce14resch01001@iith.ac.in

Email: rkg_204@yahoo.co.in

\section{Amritham Rajagopal \\ Department of Civil Engineering, IIT Hyderabad, \\ Telangana, 502285, India \\ Email: rajagopal@iith.ac.in}

\begin{abstract}
In the present work a generalised higher order shear deformation theory (GHSDT) for the flexural analysis of the functionally graded plates subjected to uniformly distributed load of varying intensities has been formulated. A finite element formulation with a confirming type isoparametric approximation has been formulated and implemented. Various types of boundary conditions have been considered for the analysis. The formulation accounts for geometric nonlinear terms in the strains. The formulation also complies with plate surface boundary conditions and does not require shear correction factors. The formulation has been validated by comparing the results with those available in the literature. Numerical results for different load parameters, volume fraction, and boundary conditions have been presented and compared with literature. Results show that the proposed GHSDT gives a better approximation to transverse shear strains and the results are closer to those obtained from analytical solutions.
\end{abstract}

Keywords: functionally graded plates; nonlinear analysis; GHSDT; rule of mixtures; power law.

Reference to this paper should be made as follows: Srividhya, S., Kumar, B., Gupta, R.K. and Rajagopal, A. (2019) 'Nonlinear analysis of FGM plates using generalised higher order shear deformation theory', Int. J. Materials and Structural Integrity, Vol. 13, Nos. 1/2/3, pp.3-15. 
Biographical notes: Singam Srividhya is a Research Scholar at the Department of Civil Engineering, IIT Hyderabad, India. Her research interests include structural analysis of composites and FGM plates.

Basant Kumar is a Scientist working for the Advanced Systems Laboratory, DRDO, Hyderabad, India. His research interests include structural design, structural dynamics, composite materials and computational mechanics and meshless methods.

R.K. Gupta is a Senior Scientist at the Advanced Systems Laboratory, DRDO, Hyderabad, India. His research interests include structural design of composite materials.

Amritham Rajagopal is an Associate Professor at the Department of Civil Engineering at IIT Hyderabad, India. His research interests include mechanics of composites, damage and fracture mechanics.

This paper is a revised and expanded version of a paper entitled 'Towards nonlocal nonlinear of FGM plates using TSDT' presented at Indian Conference on Applied Mechanics (INCAM) 2017, MNNIT Allahabad, India 5-7 July 2017.

\section{Introduction}

Functionally graded materials (FGMs) are a new class of materials which have shown potential as alternative materials that can be widely used in aerospace, nuclear, civil, automotive, optical, biomechanical, electronics, chemical, mechanical and shipbuilding industries. In fact, FGMs have been proposed, developed and successfully used in industrial applications since the 1980s (Koizumi, 1993). These advanced materials with engineered gradients of composition or properties in the preferred direction/orientation are better than homogeneous material composed of similar constituents (Jha et al., 2013). Classical composite structures suffer from discontinuity of material properties at the interface of the layers and constituents of the composite. Therefore the stress fields in these regions create interface problems and thermal stress concentrations under high temperature environments. Furthermore, large plastic deformation of the interface may trigger the initiation and propagation of cracks in the material (Vel and Batra, 2004). These problems can be addressed by use of FGMs with smooth variation of properties through the thickness. With prospects of wide range of applications, behavioural analysis of FGM's are important, however they may undergo elastic instability under mechanical loading. Therefore it is important to understand the nonlinear behaviour of FGM plates for their optimum design.

The principle developments in the field of FGMs capturing diverse areas like manufacturing aspects, homogenisation schemes and various modelling aspects were reviewed by Birman and Byrd (2007). The fact that the strength and response of an FGM also depends on the micromechanical structure embedded inside was reiterated by Emilo et al. (2016) and also that such inclusions also affects the response characteristics. A critical review of the development's in the field of FGMs was presented by Jha et al. (2013) and laid emphasis on the need to use improved 2D theoretical models in the interest of computational cost and efficient analysis. 
Many researchers have attempted to study the bending behaviour of FGM plates based on 3D elasticity solutions (Reddy and Chin, 1998; Reddy, 2000; Reddy and Cheng, 2001; Vel and Batra, 2002). All these works are limited to simply supported plates under transverse mechanical or thermal loading. Reddy (2000) presented Navier's solutions, and finite element models including geometric nonlinearity based on the third-order shear deformation theory for the analysis of FGM plates. Cheng and Batra (2000) derived the field equations for a functionally graded plate by utilising the FSDT or TSDT and simplified them for a simply supported polygonal plate.

A three dimensional elasticity solution was proposed by Kashtalyan (2004) for a simply supported FGM plate under transversely distributed load. This solution was extended to a sandwich panel with FG core by Kashtalyan and Menshykova (2008). Qian et al. (2004) studied the static and dynamic deformation of thick functionally grade elastic plates by using higher order shear and normal deformable plate theories and meshless local Petrov-Galerkin method. Ferreira et al. (2005) used a meshless method for the static analysis of a simply supported FGM plate by using a third-order shear deformation theory.

Zenkour $(2006,2007)$ presented the static response of functionally graded plates using the generalised shear deformation theory and also investigated the static problem of transverse load acting on rectangular plates using 2D trigonometric plate theory (TPT) and 3D elasticity solution. Various functions (polynomial and non-polynomial) to capture the shear deformations in thick to moderately thick isotropic, laminated and FGM plates were considered by Mantari et al. (2011) and Mantari and Soares $(2012,2013)$. On the same lines static and dynamic analysis of laminated sandwich plates and FGM plates were also carried using higher order shear deformation theories. The static and free vibration analysis of FGM plates by a sinusoidal and quasi 3D sinusoidal shear deformation theory was performed by Neves et al. (2012). Stress analysis due to thermal and mechanical loads was given by Matsunaga (2009) using a two-dimensional higherorder theory. (Khabbaz et al., 2009) provided a nonlinear solution of FGM plates using the first and third-order shear deformation theories whereas $(\mathrm{Wu}$ and $\mathrm{Li}, 2010)$ used a RMVT-based third-order shear deformation theory of multilayered FGM plates under mechanical loads. Talha and Singh (2010) investigated the free vibration and static analysis of functionally graded plates using the finite element method by employing a higher order shear deformation theory. Carrera et al. (2011) studied the effects of thickness stretching in FGM plates and shells.

From the above literature survey it is observed that a lot of research has been carried out it the field of FGM plates using higher order shear deformation theories considering linear in-plane strain variation, with an objective of better and accurate approximation of the transverse shear strain through the thickness. It is also observed that a very few papers are available which have attempted to consider the nonlinear variation of in-plane strain while using higher order theories. In the present work a generalised higher order shear deformation theory (GHSDT) has been considered for the flexural analysis of the functionally graded plate with the formulation accounting for nonlinear (von-Karman type) and constant variation of in-plane and transverse displacement respectively through the thickness. The formulation also complies with plate surface boundary conditions and does not require shear correction factors. The Young's modulus of the plate is assumed to vary with a power law through the thickness, and the Poisson's ratio is assumed to be constant. Dependence of stress and displacement fields in the plate on the power law 
index, plate thickness, boundary conditions and variation of transverse shear strains is examined and discussed. The obtained solutions are validated by comparison with the results for a homogeneous isotropic plate.

\section{Theoretical formulations}

Rasoul et al. (2012) reviewed and categorised the different composite laminate plate theories. It is explained that CPT and FSDT are unable to accurately compute transverse shear stresses of both moderately thick and thick laminated plates. It was summarised that to obtain a reasonable transverse shear stresses distribution, the global displacement theories with higher order shear deformation should be adopted. Higher order shear deformation theory introduces several new shear strain shape functions which are polynomial, trigonometric, exponential, and combination of trigonometric and exponential for modelling the displacement field for instance see Mantari et al. (2011) and Soldatos (1992). Such functions result in better approximations than the polynomial ones. The transverse displacement is assumed to be constant through the plate thickness. Here we develop equations of motion for a functionally graded plate based on Reddy's third order theory (Reddy, 2000). TSDT considers a quadratic variation of shear stresses and requires no shear correction factors.

\subsection{Displacement field and strains}

The displacement field in HSDT can be expressed as

$$
\begin{aligned}
& u(x, y, z, t)-u_{0}(x, y, t)+g(z) \varnothing_{x}(x, y, t)-f(z)\left(\varnothing_{x}+\frac{\partial w_{0}}{\partial x}\right) \\
& v(x, y, z, t)=v_{0}(x, y, t)+g(z) \varnothing_{y}(x, y, t)-f(z)\left(\varnothing_{y}+\frac{\partial w_{0}}{\partial y}\right) \\
& w(x, y, z, t)=w_{0}(x, y, t)
\end{aligned}
$$

where $\left(u_{0}, v_{0}, w_{0}\right)$ are the mid-plane displacements, $\left(\varnothing_{x}, \varnothing_{y}\right)$ denote the rotations of the transverse normal about $y$ - and $x$-axes respectively and $g(z)=z$ and $f(z)=c_{1} z^{3}$ (Reddy, 2000). By changing two functions $g(z)$ and $f(z)$ we can get different higher order theories which are also discussed in Mantari and Soares (2012). The value of $c_{1}=\frac{4}{3 h^{2}}$ is for the current formulation based on TSDT. The nonlinear strains can be expressed in the following manner

$$
\begin{aligned}
& \varepsilon_{x x}=\varepsilon_{x x}^{0}+z \varepsilon_{x x}^{1}+z^{3} \varepsilon_{x x}^{2} \\
& \varepsilon_{y y}=\varepsilon_{y y}^{0}+z \varepsilon_{y y}^{1}+z^{3} \varepsilon_{y y}^{2} \\
& \varepsilon_{x y}=\varepsilon_{x y}^{0}+z \varepsilon_{x y}^{1}+z^{3} \varepsilon_{x y}^{2} \\
& \varepsilon_{y z}=\varepsilon_{y z}^{0}+z^{2} \varepsilon_{y z}^{3} \\
& \varepsilon_{x z}=\varepsilon_{x z}^{0}+z^{2} \varepsilon_{x z}^{3}
\end{aligned}
$$

where 


$$
\begin{aligned}
& \varepsilon_{x x}^{0}=\frac{\partial u}{\partial x}+\frac{1}{2}\left(\frac{\partial w}{\partial x}\right)^{2}, \varepsilon_{x x}^{1}=\frac{\partial \theta_{x}}{\partial x}, \varepsilon_{x x}^{2}=-c_{1}\left(\frac{\partial^{2} w}{\partial x^{2}}\right) \\
& \varepsilon_{y y}^{0}=\frac{\partial v}{\partial y}+\frac{1}{2}\left(\frac{\partial w}{\partial y}\right)^{2}, \varepsilon_{y y}^{1}=\frac{\partial \theta y}{\partial y}, \varepsilon_{y y}^{2}=-c_{1}\left(\frac{\partial \theta y}{\partial y}+\frac{\partial^{2} w}{\partial y^{2}}\right) \\
& \varepsilon_{x y}^{0}=\frac{\partial u}{\partial y}+\frac{\partial v}{\partial x}+\frac{\partial w}{\partial x} \frac{\partial w}{\partial y}, \varepsilon_{x y}^{1}=\frac{\partial \theta_{x}}{\partial y}+\frac{\partial \theta_{y}}{\partial x}, \varepsilon_{x y}^{2}=-c_{1}\left(\frac{\partial \theta_{x}}{\partial y}+\frac{\partial \theta_{x}}{\partial y}+2 \frac{\partial^{2} w}{\partial x \partial y}\right) \\
& \varepsilon_{y z}^{0}=\theta_{y}+\frac{\partial w}{\partial y}, \varepsilon_{4}^{3}=-3 c_{1}\left(\theta_{y}+\frac{\partial w}{\partial y}\right) \\
& \varepsilon_{x z}^{0}=\theta_{x}+\frac{\partial w}{\partial x}, \varepsilon_{x z}^{3}=-3 c_{1}\left(\theta_{x}+\frac{\partial w}{\partial x}\right)
\end{aligned}
$$

\subsection{Constitutive relation}

A through-thickness functionally graded material plate with ceramic on the top face and metal on the bottom face is considered in the present study. The variation of the material properties like Young's modulus $E$ and Poisson's ratio $\vartheta$ is governed by a power law distribution as given in equation (4), with the co-ordinate $z$ varying between $-h / 2$ to $h / 2, h$ being the plate thickness. The volume fraction exponent $n$ can take any value between 0 to $\infty$ (Reddy, 2000).

$$
\begin{aligned}
& P(z)=P_{c} V_{c}+P_{m}\left(1-V_{c}\right) \\
& V_{c}=\left[0.5+\frac{z}{h}\right]^{n}
\end{aligned}
$$

where $P$ denotes a generic material property like modulus, $P_{c}$ and $P_{m}$ denote the property of the ceramic and metal, respectively, $h$ is the total thickness of the plate and $n$ is a parameter that dictates the material variation profile through the thickness. Here we assume that moduli $E$ and $\vartheta$ vary according to equation (4).

The constitutive relations matrix can be expressed as

$$
\left\{\begin{array}{l}
\sigma_{x x} \\
\sigma_{y y} \\
\sigma_{y z} \\
\sigma_{x z} \\
\sigma_{x y}
\end{array}\right\}=\left[\begin{array}{ccccc}
Q_{11} & Q_{12} & 0 & 0 & 0 \\
Q_{21} & Q_{11} & 0 & 0 & 0 \\
0 & 0 & Q_{44} & 0 & 0 \\
0 & 0 & 0 & Q_{55} & 0 \\
0 & 0 & 0 & 0 & Q_{66}
\end{array}\right]\left\{\begin{array}{l}
\varepsilon_{x x} \\
\varepsilon_{y y} \\
\gamma_{y z} \\
\gamma_{x z} \\
\gamma_{x y}
\end{array}\right\}
$$

where

$$
Q_{11}=\frac{E}{1-\vartheta^{2}}, Q_{12}=\vartheta Q_{11}, Q_{44}=Q_{55}=Q_{66}=\frac{E}{2(1+\vartheta)}
$$




\subsection{Equations of motion}

The governing equations of the TSDT can be derived using the principle of virtual displacement (Hamilton's principle). By substituting the stress resultants in terms of displacement into the principle of virtual displacement and integrating by parts, the equations of motion can be obtained as (Reddy, 2000)

$$
\begin{aligned}
& \delta u=\frac{\partial N_{x x}}{\partial x}+\frac{\partial N_{x y}}{\partial y}=0 \\
& \delta v=\frac{\partial N_{x y}}{\partial x}+\frac{\partial N_{y y}}{\partial y}=0 \\
& \delta w=\frac{\partial Q_{x}}{\partial x}+\frac{\partial Q_{y}}{\partial y}+\frac{\partial}{\partial x}\left(N_{x x} \frac{\partial w_{0}}{\partial x}+N_{x y} \frac{\partial w_{0}}{\partial y}\right)+\frac{\partial}{\partial y}\left(N_{x y} \frac{\partial w_{0}}{\partial x}+N_{y y} \frac{\partial w_{0}}{\partial y}\right) \\
& +c_{1}\left(\frac{\partial^{2} P_{1}}{\partial x^{2}}+\frac{\partial^{2} P_{2}}{\partial y^{2}}+2 \frac{\partial^{2} P_{6}}{\partial x \partial y}\right)=q \\
& \delta \varnothing_{x}=\frac{\partial \bar{M}_{x x}}{\partial x}+\frac{\partial \bar{M}_{x y}}{\partial y}-\bar{Q}_{x}=0 \\
& \delta \varnothing_{y}=\frac{\partial \bar{M}_{x y}}{\partial x}+\frac{\partial \bar{M}_{y y}}{\partial y}-\bar{Q}_{y}=0
\end{aligned}
$$

The stress resultants are given by

$$
\begin{aligned}
& \left(N_{\alpha \beta}, M_{\alpha \beta}, P_{\alpha \beta}\right)=\int_{-h / 2}^{h / 2} \sigma_{\alpha \beta}\left(1, z, z^{3}\right) d z \\
& \left(Q_{\alpha}, R_{\alpha}\right)=\int_{-h / 2}^{h / 2} \sigma_{\alpha z}\left(1, z^{2}\right) d z \\
& \bar{M}_{\alpha \beta}=M_{\alpha \beta}-c_{1} P_{\alpha \beta}, \bar{Q}_{\alpha}=Q_{\alpha}-c_{1} R_{\alpha}
\end{aligned}
$$

\section{Finite element formulation}

A $C^{0}$ continuous, isoparametric, confirming four noded element based on third order shear deformation plate theory with eight degrees of freedom $u, v, \Delta(w, \partial w / \partial x, \partial w / \partial y$, $\left.\partial^{2} w / \partial x \partial y,\right), \varnothing_{x}, \varnothing_{y}$ and with the Lagrange interpolation functions for $u, v, \varnothing_{x}, \varnothing_{y}$, and Hermite interpolation functions for $\Delta$ is used in the finite element analysis.

\subsection{Numerical integration}

In the present work, numerical integration technique has been implemented to evaluate the integrals for finding the material properties of FGM plate using power law distribution. Adopting numerical integration is easier, if we are trying to automate the 
finite element code. The sum of these integrand values multiplied by appropriate weights (called Gauss weights) gives an approximation to the integral.

$$
I=\int_{-1}^{1} P_{f}(z) d z \approx \sum_{i=1}^{n} w_{i} P_{f}\left(z_{i}\right)
$$

where

$z_{i} \quad$ Gauss points

$n \quad$ total no. of Gauss points

$w_{i} \quad$ Gauss weights

$P_{f}\left(z_{i}\right) \quad$ value of the integrand at the Gauss point $z_{i}$.

Using this method it is easy to find the variation of material properties along the thickness of the plate at any point. It is simpler to implement and also faster than symbolic integration in this case. To have an effective estimate the material property at any point, a quadrature rule with more number of integration points needs to be employed.

\section{Results}

The bending behaviour of a square FGM plate comprised of aluminium/zirconia under distributed transverse load is taken up for investigation. The top surface of the FGM plate is ceramic (zirconia) rich and the bottom surface is pure metal (aluminium). A schematic model of the FGM plate and its sign convention has been shown if Figure 1. The datum has been considered at the mid plane which is also the geometric mid surface of the plate. To reduce the problem size and owing to symmetry in geometry and boundary conditions, quarter plate has been considered for analysis.

- Boundary conditions

1 At $x=0$ and $x=a$ for SS 1 condition $v_{0}=w_{0}=\varnothing_{y}=0$ and for SS 3 condition $u_{0}=v_{0}=w_{0}=0$.

2 At $y=0$ and $y=a$ for SS1 condition $u_{0}=w_{0} \varnothing_{x}=0$ and for SS3 condition $u_{0}=v_{0}=w_{0}=0$.

The variation of the volume fraction of ceramic $V_{c}$ through the thickness of the FGM plate are obtained from equation (4) is presented in Figure 2 for different values of material index $n$ as defined by the power law. The non-dimensionalised central deflection is given by $\bar{w}=w / h$, load parameter: $\bar{q}=q_{0} a^{4} / E_{m} h^{4}$ and thickness coordinate: $\bar{z}=z / h$.

Table 1 Material properties

\begin{tabular}{lcccccccc}
\hline$a($ in) & $b($ in $)$ & $H($ in) & $E_{1}$ (psi) & $E_{2}$ (psi) & $G_{12}(p s i)$ & $G_{13}(p s i)$ & $G_{23}(p s i)$ & $\vartheta_{12}$ \\
\hline 12 & 12 & 0.138 & $3 \mathrm{e} 6$ & $1.28 \mathrm{e} 6$ & $0.37 \mathrm{e} 6$ & $0.37 \mathrm{e} 6$ & $0.37 \mathrm{e} 6$ & 0.3 \\
\hline
\end{tabular}


Figure 1 Geometric details of the square plate with quarter symmetry and axes convention followed (see online version for colours)

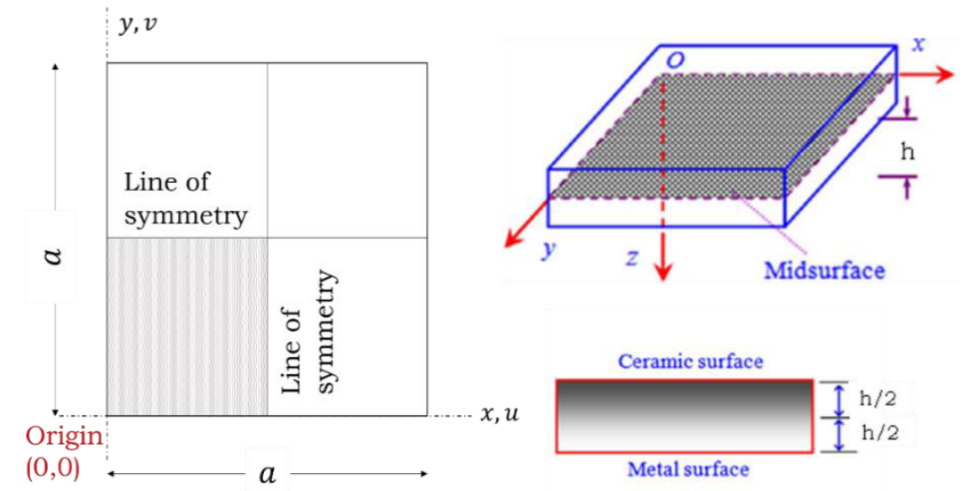

Figure 2 Typical variation of volume fraction through the thickness based on power law (see online version for colours)

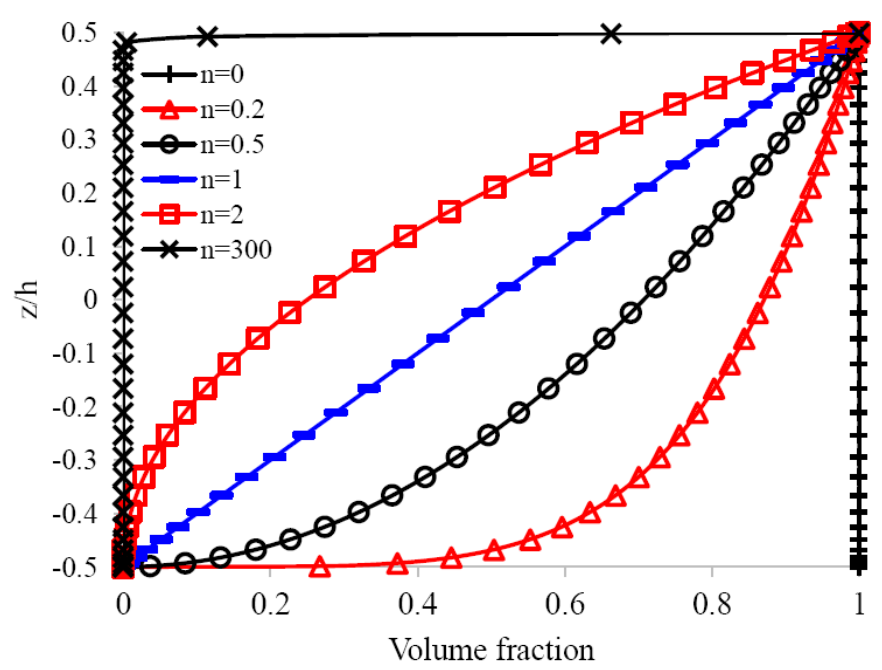

\subsection{Example 1}

To validate the nonlinear code a square orthotropic plate under uniformly distributed load has been considered and the details are presented below. The results obtained from the analysis have been compared with those available in literature and have been tabulated in Table 2 and pictorially shown in Figure 3. 
Figure 3 Nonlinear deflections versus load parameter for different boundary conditions (see online version for colours)

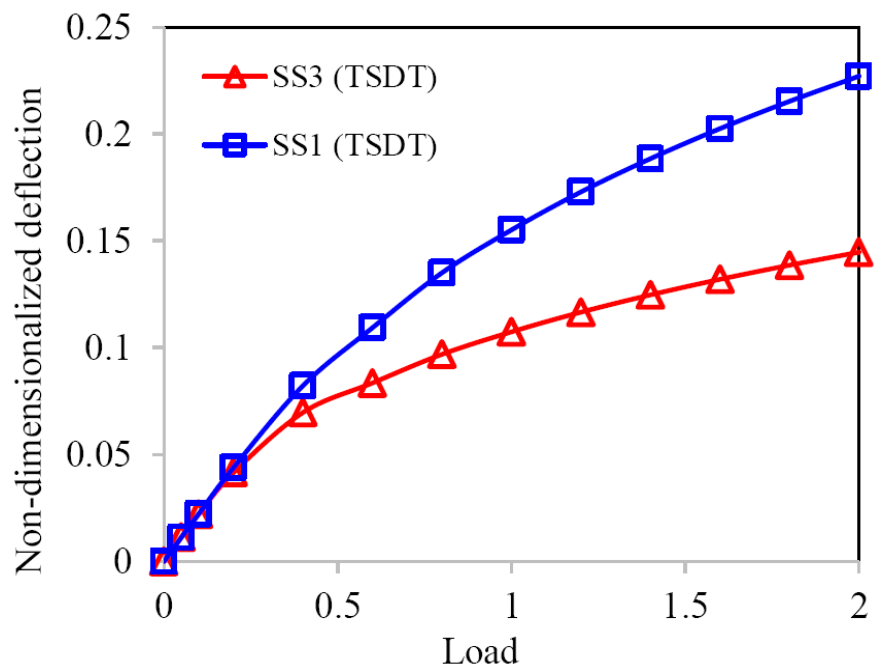

Table 2 Comparison of the central deflections obtained with results from literature

\begin{tabular}{|c|c|c|c|c|c|c|c|c|}
\hline \multirow[b]{2}{*}{$q_{0}$} & \multicolumn{4}{|c|}{$S S 3$} & \multicolumn{4}{|c|}{ SS1 } \\
\hline & $C P T$ & $F S D T$ & $\begin{array}{l}\text { Reddy } \\
(2015)\end{array}$ & $\begin{array}{c}T S D T \\
\text { (present) }\end{array}$ & $C P T$ & $F S D T$ & $\begin{array}{l}\text { Reddy } \\
(2015)\end{array}$ & $\begin{array}{c}\text { TSDT } \\
\text { (present) }\end{array}$ \\
\hline 0.05 & 0.0112 & 0.0114 & 0.0113 & 0.0113 & 0.0113 & 0.0113 & 0.0113 & 0.0113 \\
\hline 0.1 & 0.0217 & 0.0222 & 0.0218 & 0.0221 & 0.0224 & 0.0224 & 0.0224 & 0.0223 \\
\hline 0.2 & 0.0395 & 0.0418 & 0.0397 & 0.0416 & 0.0438 & 0.0442 & 0.0439 & 0.0439 \\
\hline 0.4 & 0.0648 & 0.0700 & 0.065 & 0.0697 & 0.0812 & 0.0831 & 0.0815 & 0.0822 \\
\hline 0.6 & 0.0823 & 0.0839 & 0.0824 & 0.0835 & 0.1116 & 0.1113 & 0.1122 & 0.1094 \\
\hline 0.8 & 0.0957 & 0.0973 & 0.0959 & 0.0969 & 0.1367 & 0.1385 & 0.1377 & 0.1351 \\
\hline 1 & 0.1068 & 0.1078 & 0.1069 & 0.1074 & 0.1581 & 0.1598 & 0.1594 & 0.1551 \\
\hline 1.2 & 0.1162 & 0.1169 & 0.1162 & 0.1166 & 0.1767 & 0.1789 & 0.1783 & 0.1729 \\
\hline 1.4 & 0.1245 & 0.1250 & 0.1244 & 0.1247 & 0.1932 & 0.1956 & 0.1951 & 0.1885 \\
\hline 1.6 & 0.1318 & 0.1323 & 0.1318 & 0.1320 & 0.2081 & 0.2107 & 0.2103 & 0.2025 \\
\hline 1.8 & 0.1385 & 0.1389 & 0.1384 & 0.1386 & 0.2217 & 0.2246 & 0.2241 & 0.2153 \\
\hline 2 & 0.1447 & 0.1449 & 0.1445 & 0.1447 & 0.2343 & 0.2373 & 0.2370 & 0.2271 \\
\hline
\end{tabular}

\subsection{Example 2}

In the example below, $\mathrm{Al} / \mathrm{Zr}$ FGM plate is considered and non-dimensionalised linear central deflections are tabulated for various load parameters and compared with different theories and with results available in literature as shown in Table 3. 
Table 3 Material properties

\begin{tabular}{lcc}
\hline Property & Young's modulus & Poisson's ratio \\
\hline Aluminium & $70 \mathrm{Gpa}$ & 0.3 \\
Zirconia & $151 \mathrm{Gpa}$ & 0.3 \\
\hline
\end{tabular}

\subsection{Example 3}

In the example below, $\mathrm{Al} / \mathrm{Zr}$ FGM plate is considered and non-dimensionalised linear and nonlinear central deflections are plotted against various load parameters for different power index values as shown below in Figure 4 and Figure 5.

Figure 4 Non-dimensionalised linear deflection versus load parameter (see online version for colours)

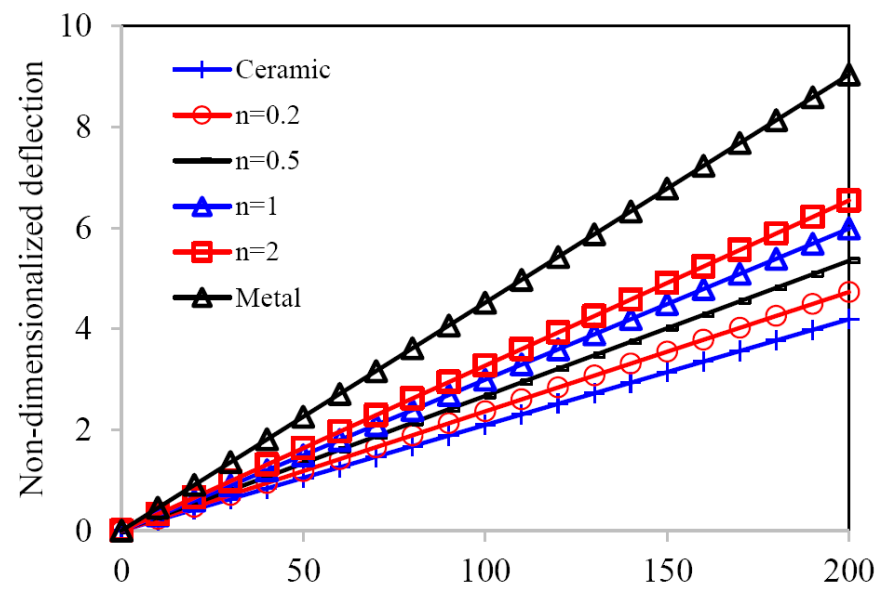

Figure 5 Non-dimensionalised nonlinear deflection versus load parameter (see online version for colours)

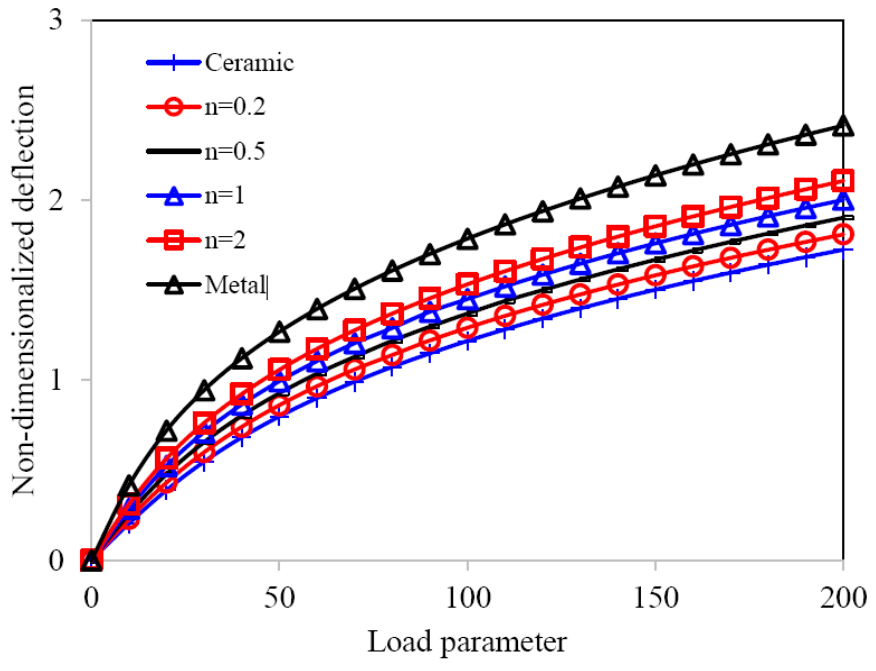


From the linear and nonlinear results if we compare the non-dimensionalised deflections the linear analysis results are higher than that of nonlinear analysis results. The deflections are increasing with the increase in the power index value in all the examples. From Figure 3 it is clear that SS3 boundary condition yields higher deflections than in SS1 case because of increase in stiffness in SS1 because of constraints. From Table 4 we can see the comparison between FSDT and TSDT. In Figure 4 plots of the linear non-dimensional centre deflections versus load parameter for different values of the power-law index are presented. As metal plate $(n=\infty)$ has lower stiffness compared to the ceramic plate $(n=0)$, it is expected to deflect more than the ceramic plate; and for all other intermediate values of $n$, the deflections increase with increase in $n$. Figure 5 contains plots of nonlinear non-dimensional centre deflection versus load parameter for different values of the power-law index. To show the effect of nonlinearity the deflections are plotted up to a very high value of $\operatorname{load}(\bar{q}=200)$. The deflections are becoming completely nonlinear for a value of $\bar{q}$ greater than 50 for all the power-law index values. The non-dimensional deflection increases with increase in the power-law index value and percentage difference between extreme values is about $20-40 \%$.

Table 4 Non-dimensionalised linear deflections versus $\bar{q}$ for various $n$ values

\begin{tabular}{cccccccc}
\hline \multirow{q}{*}{} & Theory & \multicolumn{7}{c}{ Power index ' $n$ ' } \\
\cline { 3 - 8 } & & ceramic & 0.2 & 0.5 & 1 & 2 & metal \\
\hline 1 & TSDT & 0.0209 & 0.0236 & 0.0267 & 0.0299 & 0.0327 & 0.0452 \\
& FSDT & 0.0207 & 0.0234 & 0.0265 & 0.0296 & 0.0324 & 0.0447 \\
\multirow{4}{*}{6} & Ferreira et al. (2005) & 0.0205 & - & 0.0262 & 0.0294 & 0.0323 & 0.0443 \\
& TSDT & 0.1257 & 0.1419 & 0.1604 & 0.1796 & 0.1963 & 0.2711 \\
\multirow{2}{*}{12} & FSDT & 0.1244 & 0.1405 & 0.1590 & 0.1778 & 0.1941 & 0.2683 \\
& TSDT & 0.2513 & 0.2837 & 0.3208 & 0.3591 & 0.3925 & 0.5421 \\
18 & FSDT & 0.2488 & 0.2811 & 0.3179 & 0.3557 & 0.3882 & 0.5367 \\
& TSDT & 0.3770 & 0.4256 & 0.4812 & 0.5387 & 0.5888 & 0.8132 \\
24 & FSDT & 0.3732 & 0.4216 & 0.4769 & 0.5335 & 0.5823 & 0.8050 \\
& TSDT & 0.5026 & 0.5674 & 0.6417 & 0.7183 & 0.7851 & 1.0842 \\
30 & FSDT & 0.4976 & 0.5621 & 0.6358 & 0.7114 & 0.7764 & 1.0733 \\
& TSDT & 0.6283 & 0.7093 & 0.8021 & 0.8978 & 0.9814 & 1.3553 \\
& FSDT & 0.6220 & 0.7026 & 0.7948 & 0.8892 & 0.9706 & 1.3417 \\
\hline
\end{tabular}

\section{Conclusions}

The present study is of a generalised higher order shear deformation theory that accounts for adequate distribution of the transverse shear strains through the plate thickness which accounts for nonlinearity of strains is presented for FGM plates. The behaviour of these plates is studied using finite element analysis and numerical integration technique is used to find the properties through the thickness. The results produced using this theory are validated with literature. Example 1 is presented for validation of the results. From example 2 the importance of using HSDT is presented and from example 3 the effect of 
nonlinearity is shown. A comparison with two different boundary conditions is also shown.

\section{References}

Birman, V. and Byrd, L.W. (2007) 'Modelling and analysis of functionally graded materials and structures', ASME Appl. Mech. Rev., Vol. 60, pp.195-216.

Brischetto, S. and Carrera, E. (2008) 'Advanced mixed theories for bending analysis of functionally graded plates', Computers and Structures, Vol. 88, pp.1474-1483.

Carrera, E., Brischetto, S., Cinefra, M. and Soave, M. (2011) 'Effects of thickness stretching in functionally graded plates and shells', Composites: Part B, Vol. 42, pp.123-133.

Cheng, Z-Q. and Batra R.C. (2000) 'Deflection relationships between the homogeneous Kirchhoff plate theory and different functionally graded plate theories', Arch. Mech., Vol. 52, pp.43-58.

Cinefra, M. and Soave, M. (2011) 'Accurate vibration analysis of multi-layered plates made of functionally graded materials', Mechanics of advanced Materials and Structures, Vol. 18, No. 1, pp.3-13.

Emilio, P.S., Evangelos, K.L. and Victor, N.K. (2016) 'Influence of particle arrangement on the stiffness and thermal expansion coefficient of aluminium-epoxy composites', Int. J. of Materials and Structural Integrity, Vol. 10, No. 4, pp.133-156.

Ferreira, A.J.M., Batra, R.C., Roque, C.M.C., Qian, L.F. and Martins, P.A.L.S. (2005) 'Static analysis of functionally graded plates using third-order shear deformation theory', Composite Structures, Vol. 69, pp.449-457.

Jha, D.K., Kant, T. and Singh, R.K. (2013) 'A critical review of recent research on functionally graded plates', Composite Structures, Vol. 96, pp.833-849.

Kashtalyan, M. (2004) 'Three-dimensional elasticity solution for bending of functionally graded plates', European Journal of Mechanics -A/Solids, Vol. 23, pp.853-864.

Kashtalyan, M. and Menshykova, M. (2008) 'Three-dimensional elasticity solution for sandwich panels with a functionally graded core', Composite Structures, Vol. 87, pp.36-43.

Khabbaz, R.S., Manshadi, B.D. and Abedian, A. (2009) 'Nonlinear analysis of FGM plates under pressure loads using the higher-order shear deformation theories', Composite Structures, Vol. 89, No. 3, pp.333-344.

Koizumi, M. (1993) 'The concept of FGM', Ceramic Transactions, Functionally Gradient Materials, Vol. 34, pp.3-10.

Mantari, J.L. and Soares, C.G. (2012) 'Generalized hybrid quasi-3D shear deformation theory for the static analysis of advanced composite plates', Composite Structures, Vol. 94, No. 8, pp.2561-2575.

Mantari, J.L. and Soares, C.G. (2013) 'Finite element formulation of a generalized higher order shear deformation theory for advanced composite plates', Composite Structures, Vol. 96, pp.545-553.

Mantari, J.L., Oktem, A.S. and Soares, C.G. (2011) 'Static and dynamic analysis of laminated composite and sandwich plates and shells by using a new higher order shear deformation theory', Composite Structures, Vol. 94, pp.37-49.

Matsunaga, H. (2008) 'Free vibration and stability of functionally graded plates according to 2D higher-order deformation theory', Composite Structures, Vol. 82, pp.256-270.

Matsunaga, H. (2009) 'Stress analysis of functionally graded plates subjected to thermal and mechanical loadings', Composite Structures, Vol. 87, pp.344-357.

Neves, A.M.A., Ferreira, A.J.M., Carrera, E., Roque, C.M.C., Cinefra, M. and Jorge, R.M.N. (2012) 'A quasi-3D sinusoidal shear deformation theory for the static and free vibration analysis of functionally graded plates', Composites: Part B, Vol. 43, pp.711-725. 
Qian, L.F., Batra, R.C. and Chen, L.M. (2004) 'Static and dynamic deformations of thick functionally graded elastic plates by using higher-order shear and normal deformable plate theory and meshless local Petrov Galerkin theory', Composites: Part B, Vol. 35, pp.685-697.

Rasoul, K., Siamak, N., Philip, S. and John, V., (2012) 'The development of laminated composite plate theories: a review', Journal of Material Sciences, Vol. 47, pp.5901-5910.

Reddy, J.N. (1986) A Refined Shear Deformation Theory for the Analysis of Laminated Plates, NASA Report, 3955.

Reddy, J.N. (2000) 'Analysis of functionally graded plates', International Journal of Numerical Methods in Engineering, Vol. 47, pp.663-684.

Reddy, J.N. (2015) An Introduction to Nonlinear Finite Element Analyses, Oxford University Press, Oxford, UK.

Reddy, J.N. and Cheng, Z-Q. (2001) 'Three dimensional thermo mechanical deformations of functionally graded rectangular plates', European Journal of Mechanics and Solids, Vol. 20, pp.841-855.

Reddy, J.N. and Chin, C.D. (1998) 'Thermo mechanical analysis of functionally graded cylinders and plates', Journal of Thermal Stresses, Vol. 21, pp.593-626.

Soldatos, K.P. (1992) 'A transverse shear deformation theory for homogeneous monoclinic plates', Acta Mechanica, Vol. 94, pp.195-200.

Talha, M. and Singh, B.N. (2010) 'Static response and free vibration analysis of FGM plates using higher order shear deformation theory', Appl. Math Model, Vol. 34, pp.3991-4011.

Vel, S.S. and Batra, R.C. (2002) 'Exact solution for thermo-elastic deformations of functionally graded thick rectangular plates', AIAA Journal, Vol. 40, No. 7, pp.1421-1433.

Vel, S.S. and Batra, R.C. (2004) 'Three-dimensional exact solution for the vibration of functionally graded rectangular plates', Journal of Sound and Vibrations, Vol. 272, pp.703-730.

Wu, C.P. and Li, H.Y. (2010) 'An RMVT-based third-order shear deformation theory of multi-layered functionally graded material plates', Composite Structures, Vol. 92, pp.2591-2605.

Zenkour, A.M. (2006) 'Generalized shear deformation theory for bending analysis of functionally graded plates', Applied Mathematical Modelling, Vol. 30, pp.67-84.

Zenkour, A.M. (2007) 'Benchmark trigonometric and 3-D elasticity solutions for an exponentially graded thick rectangular plate’, Applied Mathematical Modelling, Vol. 77, pp.197-214. 